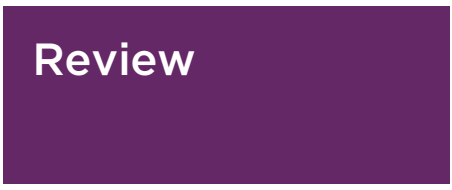

\title{
Why is type 1 diabetes increasing?
}

\author{
Francesco Maria Egro
}

Department of Cellular and Molecular Medicine, University of Bristol, 53 Arley Hill, Bristol BS6 5PJ, UK

Correspondence should be addressed to F M Egro Email

francescoegro@gmail.com

\begin{abstract}
A series of studies have reported a constant global rise in the incidence of type 1 diabetes. Epidemiological and immunological studies have demonstrated that environmental factors may influence the pathogenesis, leading to a cell-mediated pancreatic $\beta$-cell destruction associated with humoral immunity. The search for the triggering factor(s) has been going on for the past century, and yet they are still unknown. This review provides an overview of some of the most well-known theories found in the literature: hygiene, viral, vitamin D deficiency, breast milk and cow's milk hypotheses. Although the hygiene hypothesis appears to be the most promising, positive evidence from animal, human and epidemiological studies precludes us from completely discarding any of the other hypotheses. Moreover, due to contrasting evidence in the literature, a single factor is unlikely to cause an increase in the incidence of diabetes all over the world, which suggests that a multifactorial process might be involved. Although the immunological mechanisms are still unclear, there seems to be some overlap between the various hypotheses. It is thought that the emphasis should be shifted from a single to a multifactorial process and that perhaps the 'balance shift' model should be considered as a possible explanation for the rise in the incidence of type 1 diabetes.
\end{abstract}

\author{
Key Words \\ - diabetes 1 \\ - review \\ - mechanism \\ - increase \\ - rise \\ - immunology \\ - balance shift \\ - hygiene \\ - vitamin D deficiency \\ - breast milk \\ - cow's milk \\ hypotheses
}

- viral

Journal of Molecular

Endocrinology

(2013) 51, R1-R13

\section{Introduction}

Type 1 diabetes has been on the rise since the 20th century. Gale (2002b) demonstrated how the data point towards a stable and low incidence in the first half of the century, followed by a clear rise in the second half. Onkamo et al. (1999) reported that the global incidence of type 1 diabetes is increasing by 3\% per year. The DIAMOND Project Group (2006) estimated a global annual increase in incidence of 2.8\% from 1990 to 1999.

There has been a lot of debate, and contrasting ideas have been brought forward in the literature to explain this rapid increase in the incidence of type 1 diabetes. A variety of hypotheses try to explain this lability in the immune system, which leads to autoimmunity of the pancreatic $\beta$-cells. This review attempts to explore and summarise the current evidence in the literature.

\section{Hygiene hypothesis}

One of the most credited theories is the hygiene hypothesis brought forward by Strachan (1989). The results have shown that exposure to a variety of infectious agents during early childhood might be protective (Strachan 1989) and not only in asthma, but in type 1 diabetes as well (Kolb \& Elliott 1994). Strong evidence from a variety of epidemiological studies has indicated a constant increase in the incidence of type 1 diabetes (Gale 2002b, DIAMOND Project Group 2006, Soltesz et al. 2007), contrasted by a gradual decrease in the incidence of infectious diseases, such as tuberculosis, mumps, measles, hepatitis $\mathrm{A}$ and enterovirus infections (Bach 2002, Tracy et al. 2010).

Published by Bioscientifica Ltd 
Studies have shown that non-obese diabetic (NOD) mice develop type 1 diabetes at a greater rate when bred among pathogen-free environment-bred animals. Furthermore, the incidence increases (40-80\%) when they are bred in isolation (Bach 2002). The development of diabetes in NOD mice can be prevented following infection with a variety of pathogens, such as mycobacteria (Qin etal.2004), lymphocytic choriomeningitis viruses (LCMVs; Christen et al. 2004a), lactate dehydrogenase viruses (Takei et al. 1992) and parasites such as Schistosoma (Cooke et al. 1999).

The underlying mechanisms are still unclear, but an attempt will be made to summarise the current evidence (Fig. 1).

\section{Bystander suppression}

An infectious epitope may induce the suppression of autoreactive $\mathrm{T}$ cells by interacting on the same antigenpresenting cell (APC) with both regulatory T cells (Tregs) and autoreactive T cells. Tregs can act as well by producing IL10 and TGF $\beta$ (TFGB1), which down-regulate T-helper 1 (Th1) cells. This process has been observed in animal models, such as the NOD mice, where Tregs can be induced by oral antigen administration. These T cells act via TGF $\beta$ and cause active suppression in a non-specific fashion, therefore causing bystander suppression (Bach 2005).

\section{Toll-like receptors}

Ligand binding to toll-like receptors (TLRs) causes the stimulation of APCs. This causes the activation of transcription factors that lead to the production of cytokines and chemokines and up-regulation of costimulatory molecules CD80 and CD86. This up-regulation leads to the expression of major histocompatibility complex (MHC), which in turn will increase the activation of naïve $\mathrm{CD}^{+}{ }^{+} \mathrm{T}$ cells. Ligand binding to TLRs causes the stimulation of mononuclear cells, which produce

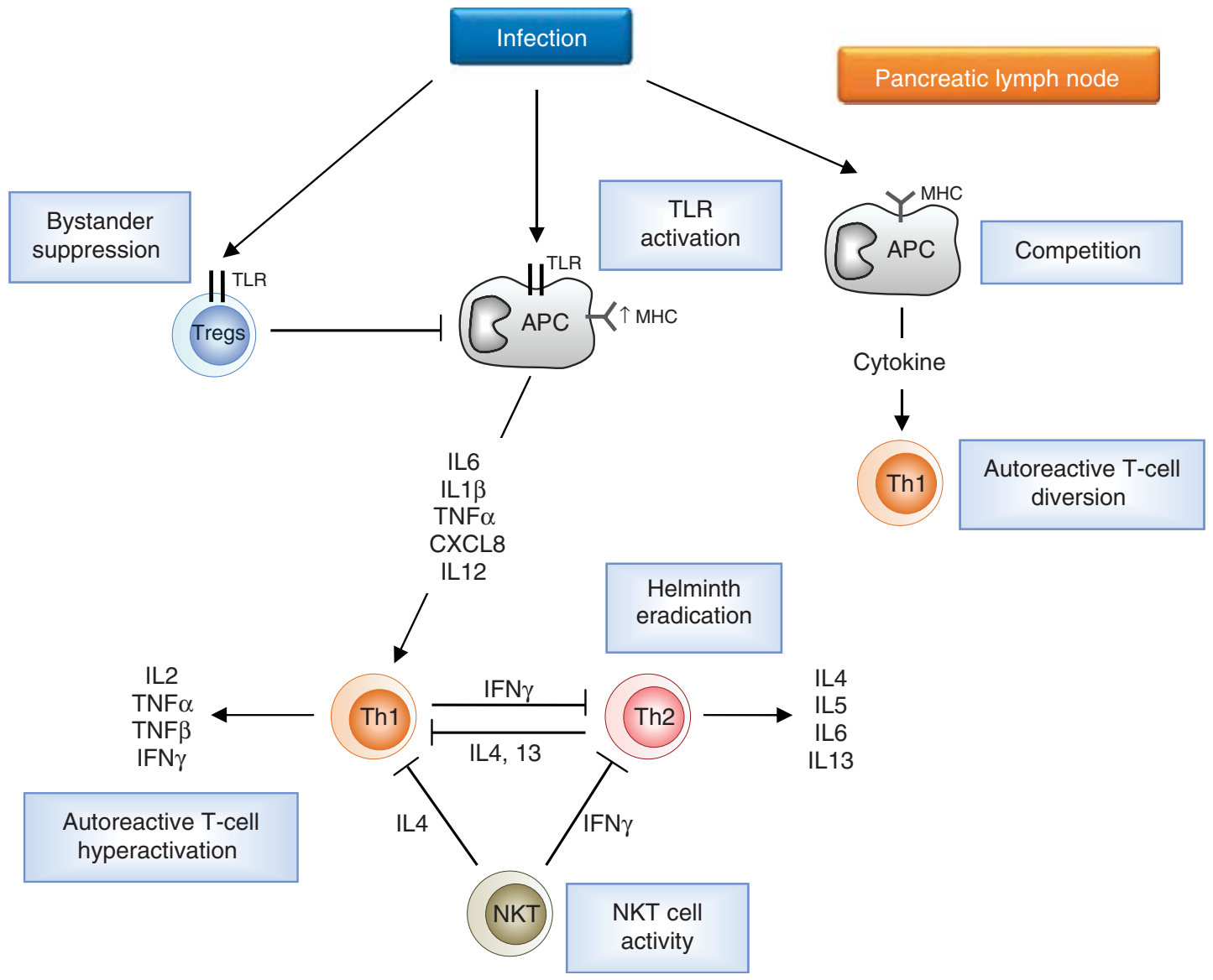

Figure 1

A schematic summary of the possible immunological mechanisms underlying the hygiene hypothesis. APC, antigen-presenting cell; Tregs, regulatory T cells; Th1, type 1 helper T cell; $N K T$, natural killer T cell; TLR, toll-like receptor; $M H C$, major histocompatibility complex. Full colour version of this figure available via http://dx.doi.org/10.1530/JME-13-0067. http://jme.endocrinology-journals.org DOI: 10.1530/JME-13-0067
() 2013 Society for Endocrinology Printed in Great Britain
Published by Bioscientifica Ltd. 
cytokines. These might cause a down-regulation in the autoimmune process. Studies have shown that protection from diabetes in NOD mice can be achieved by the use of CpG motif associated with a DNA construct, encoding heat shock proteins. The production of IL10 by monocytes might play a role as well (Quintana et al. 2000).

\section{Natural killer T cells}

These cells are thought to have a regulatory role in the immune system by producing IFN $\gamma$ (IFNG) and other cytokines such as IL2, IL4 and TNF $\alpha$ (TNF). Poulton et al. (2001) identified a major natural killer T (NKT) cell deficiency in NOD mice thymus, suggesting a possible involvement in the susceptibility of diabetes. Furthermore, studies have shown that $C d 1 d^{-/-}\left(C d 1 d 1^{-/-}\right)$NOD mice present a diminished protective state compared with the wild-type mice. CD1D is a glycoprotein expressed on the surface of APCs and is involved, in association with MHC, in the presentation of antigens to NKT cells. Therefore, if CD1D is not present, APCs cannot present antigens to NKT cells, therefore reducing their regulatory and protective role in the development of type 1 diabetes (Bach 2005).

\section{Competition for immune cells}

Anti-infectious responses may compete for APCs, for binding of antigenic peptides to MHC molecules or for cytokines, which are needed for lymphocyte differentiation and homoeostasis. We can, therefore, hypothesise that stronger immune responses, in this case anti-infectious, will compete for homoeostatic signals against weaker responses, such as those against autoantigens (Theofilopoulos et al. 2001). Evidence for this hypothesis has been reported in a study on NOD mice, where complete Freund's adjuvant, an adjuvant composed of inactivated mycobacteria, exhibited an anti-homoeostatic effect by inhibiting the production of unrelated T cells (King et al. 2004).

\section{Autoreactive T-cell diversion}

Autoreactive T cells might be kept away from the site of autoimmunity by infection. Studies have shown that LCMV infection has a protective effect on prediabetic NOD and LCMV-immune RIP-LCMV mice. Interestingly, lymphocytic islet infiltration was decreased following LCMV secondary infection, and a more than fivefold increase in the expression of IP10 (CXCL10) occurred in the pancreatic draining lymph nodes than in the islets.
This demonstrated that T-cell recruitment occurred from the islets to the pancreatic lymph nodes, via the expression of chemokine IP10, leading to the abrogation of type 1 diabetes (Christen et al. 2004a).

\section{Autoreactive T-cell hyperactivation}

Christen et al. (2004a) showed that viral titre influences the antigen load in pancreatic draining lymph nodes, suggesting that antigens drive the induction of apoptosis of autoreactive $\mathrm{T}$ cells, reducing the number of these species. Thus, hyperactivation of autoreactive lymphocytes might result in protective effects against type 1 diabetes. Further evidence comes from a study carried out by Qin et al. (2004), where administration of a Bacille Calmette-Guérin (BCG) mycobacterial preparation resulted in a protective effect by early up-regulation of IFN $\gamma$ and TNF $\alpha$, which led to apoptosis of autoreactive $\mathrm{T}$ cells via the TNF-induced and Fas-FasL-mediated pathways. This leads to the abrogation of diabetes.

\section{Helminth eradication}

In humans, helminths reduce insulitis by inducing the secretion of Th2-type cytokines (skewing $\mathrm{T}$ cells towards the production of IL4, IL10 and IL13 associated with eosinophilia and high IgE antibody levels; Liu et al. 2009, Zaccone et al. 2010) In 1947, Stoll stated that the prevalence of helminth infections was 31\% in the USA and $36 \%$ in Europe. The most common species was Enterobius vermicularis (also known as pinworm). Unfortunately, there is no exact value indicating today's prevalence. However, Gale (2002a) reported a series of studies that provide evidence of a decline in the incidence of helminth infections. This decrease is associated (not necessarily causally) with improved hygiene, protection by a high number of people in the household, early social mixing and pets. All these factors and the geographical distribution fit in with the hygiene hypothesis. In fact, helminths might be protective agents, since a Th2-helminth-induced response might balance the autoimmunity-enhanced Th1 response.

\section{Viral hypothesis}

Another much credited hypothesis is the viral hypothesis, which states that a variety of viruses (including enterovirus, rubella virus, mumps virus, rotavirus and cytomegalovirus (CMV)) may initiate or accelerate the autoimmune process of type 1 diabetes.

Published by Bioscientifica Ltd. 
The question as to how these pathogens cause the destruction of islet $\beta$-cells is still uncertain. However, a variety of mechanisms have been put forward and are summarised in Fig. 2.

\section{Direct infection}

Viral infection of the $\beta$-cells induces cell cytolysis, which leads to a raised immune response and inflammation.

\section{Molecular mimicry}

Sequences between foreign and self-peptides are similar and are sufficient enough to result in the cross-activation of autoreactive $\mathrm{T}$ or $\mathrm{B}$ cells by pathogen-derived peptides. In this case, viral peptides would lead to the destruction of $\beta$-cells via the cross-activation of autoreactive $\mathrm{T}$ cells (Honeyman et al. 2010). Interestingly, Christen et al. (2004b) have demonstrated that viral epitopes do not initiate type 1 diabetes, but may accelerate its development.

\section{Bystander activation of autoreactive T cells}

Viral infections cause the activation of APCs, which could potentially activate preprimed autoreactive $\mathrm{T}$ cells by the secretion of cytokines. This could have effects on the enhancement of autoreactive $\mathrm{T}$ cells and increase the production of Th1-like cytokines (such as IFN $\gamma$ and TNF), leading to the damage of $\beta$-cells. In addition, virus-specific

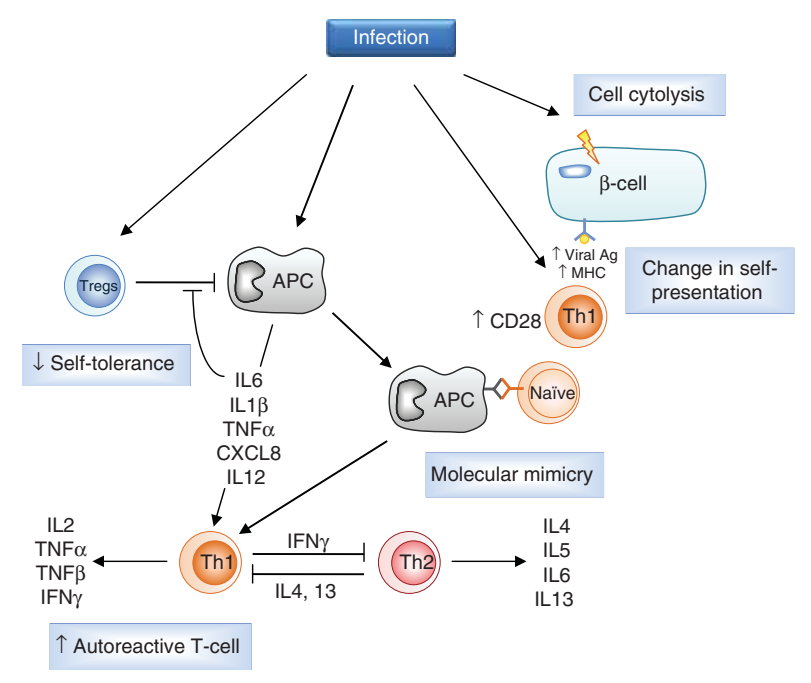

Figure 2

A schematic summary of the possible immunological mechanisms underlying the viral hypothesis. Full colour version of this figure available via http://dx.doi.org/10.1530/JME-13-0067.
T cells might be able to initiate bystander activation too. For example, viral infections lead to anti-viral immune responses that can also lead to the self-recognition of $\beta$-cells. Once activated, virus-specific T cells may migrate to infected areas (e.g. pancreas), where they are presented viral epitopes via MHC class I and II molecules found on infected cells. $\mathrm{CD}^{+} \mathrm{T}$ cells then identify these infected cells and release cytotoxic granules, leading to cell death. Cytokines such as TNF $\alpha$ and TNF $\beta$ and nitric oxide are then released by the $\mathrm{CD}^{+} \mathrm{T}$ cells, inflammatory cells (macrophages) and dying cells, which may induce apoptosis of the uninfected neighbouring cells, resulting in further damage at the site of infection (Fujinami et al. 2006, van der Werf et al. 2007).

\section{Change in self-presentation}

This could lead to the recognition of $\beta$-cells as foreign by the immune system, provoking autoimmunity. This may be caused by the expression of viral antigens by $\beta$-cells, increased exposure of these antigens to the immune system or up-regulation of molecules such as costimulatory CD80 on APCs and CD28 on T cells and both MHC class molecules expressed on the host's cells (van der Werf et al. 2007).

\section{Down-regulation of self-tolerance}

Alteration of the immune system is possibly caused by the activation of polyclonal lymphocytes, leading to the production of autoantibodies.

A summary of the evidence for individual pathogens is presented here.

\section{Enteroviruses}

Evidence supports the theory that enteroviruses play a major role in the development of type 1 diabetes (Yeung et al. 2011), with coxsackie virus B4 (CVB4) being the most common strain in prediabetic and diabetic patients. Studies have reported an increase in the number of enterovirus infections in prediabetic children associated with an increase in the levels of viral RNA and autoantibodies (islet-cell antibodies (ICAs) and glutamic acid decarboxylase antibodies (GADAs); Lonnrot et al. 2000b). Another study has prospectively examined a cohort of children predisposed to develop type 1 diabetes. The study has shown that enterovirus infections could be detected before (6 months) the appearance of autoantibodies against $\beta$-cells, providing further evidence of the role of

Published by Bioscientifica Ltd. 
enteroviruses in type 1 diabetes (Lonnrot et al. 2000a). Furthermore, infections are more common in siblings developing the disease than in sibling who do not, and enterocyte antibodies are present during pregnancy in those mothers who give birth to children developing type 1 diabetes at a later stage (Filippi \& von Herrath 2008). Dotta et al. (2007) analysed pancreatic specimens obtained from six type 1 diabetic and 26 control organ donors and identified CVB4 in three of the six diabetic patients. Oikarinen et al. (2008) gave further evidence by analysing upper intestinal biopsy specimens and identifying enteroviruses in $75 \%$ of the cases (9 of 12 diabetic patients). A series of mechanisms have been reported for enteroviruses. Flodstrom et al. (2003) showed that acute CVB3 infection leads to the cytolysis of $\beta$-cells when the anti-viral IFN response is down-regulated, resulting in type 1 diabetes. In addition, CVB infection has been shown to lead to the expansion of autoreactive $\mathrm{T}$ cells caused by the presentation of autoantigens to $\mathrm{T}$ cells (Horwitz et al. 2004). A variety of studies have demonstrated that molecular mimicry might be the underlying mechanism for the development of type 1 diabetes. Harkonen et al. (2002) identified in both NOD mice and humans (7\%) cross-reactivity between the autoantibodies insulinoma antigen 2 (IA-2)/IAR and the capsid of enteroviruses. In addition, the P2-C sequence of CVB4 shows similarities with human GAD (GAD1; Kaufman et al. 1992), which is recognised by T cells of patients at risk for developing diabetes, and interestingly these patients responded not only to GAD but to CVB peptide as well (Atkinson et al. 1994). However, patients' GAD-positive sera do not cross-react with the P2-C sequence (Richter et al. 1994). Furthermore, congenic B10.H2g7 mice (carrying NOD MHC allele but lacking other susceptibility factors) do not develop diabetes when infected with CVB4. However, it was induced in BDC2.5 transgenic mice, which express a T-cell receptor specific to an islet antigen, but it does not cross-react with the P2-C sequence of CVB4 (Filippi \& von Herrath 2008).

Bystander activation of autoreactive T cells is another mechanism reported in the literature to explain the initiation of type 1 diabetes. CVB4 infection has been found to cause the phagocytosis of $\beta$-cells by macrophages and, interestingly, adoptive transfer of APCs isolated from CVB4-infected mice induced diabetes (Horwitz et al. 2004). Further evidence comes from the inability of the activated T cells of BDC2.5 mice to induce diabetes in the absence of CVB4 infection (Horwitz et al. 1998). This suggests not only bystander involvement, but also the importance of macrophages as initiators of the disease and that multiple environmental factors could cause it.

A word of caution though is required in the accusation of these viruses. Recent studies have shown the prevention of diabetes by inducing the proliferation of Tregs (Diana et al. 2011, Larsson et al. 2013). Even within the same viral species, different strains may have different effects on the development of the disease. As described above, CVB4 has been shown to induce diabetes, whereas CVB3 has been shown in other studies to play a protective role (Serreze et al. 2000, Tracy et al. 2002). Timing of the infection also appears to be of great importance (Serreze et al. 2000).

\section{Rotaviruses}

These viruses are the leading cause of childhood gastroenteritis, but have also been associated with type 1 diabetes. Seven species have been identified: A, B, C, D, $\mathrm{E}, \mathrm{F}$ and $\mathrm{G}$, with A being the most common (Flint et al. 2009). Honeyman et al. (2000) showed a clear association between rotavirus infection in children at risk of developing type 1 diabetes and increased production of the autoantibodies IA-2 (IA-2A), insulin autoantibodies (IAAs) and GADAs. In vitro studies on NOD mouse islets have suggested that rotaviruses might induce type 1 diabetes by direct infection of the $\beta$-cells. However, human rotaviruses were successful in replication only in monkey islets (Coulson et al. 2002). Another mechanism that has been proposed is molecular mimicry. Honeyman et al. (2010) showed that rotaviral VP7 protein shows high homology with IAAs, IA-2 and GAD65. T cells cross-react with VP7 peptides and epitopes of IA-2 and GAD65, which bind strongly to HLA-DRB $1{ }^{*} 04$, conferring susceptibility to T1D. However, the extent of the role of rotaviruses in the development of type 1 diabetes is still unclear.

\section{Cytomegalovirus}

The first report of an association occurred in 1979, when a child suffering from congenital CMV infection developed type 1 diabetes. This correlation was confirmed by Smelt et al. (2012), who showed that CMV can infect human $\beta$-cells, inducing the expression of inflammatory factors and cytokines.

A mechanism that might explain the induction of type 1 diabetes by CMV is the bystander activation of autoreactive T cells. van der Werf et al. (2003) reported an increase in the proliferation of $\mathrm{T}$ cells (around 50\%) in ratspecific CMV (RCMV)-infected splenocytes, following in vitro restimulation with RCMV-infected fibroblasts.

Published by Bioscientifica Ltd. 
Unfortunately, there is still no causal evidence between CMV and type 1 diabetes; therefore, as Bach (2005) stated in his review, the role of CMV is still elusive.

\section{Mumps virus}

This virus causes epidemic parotitis, but has also been associated with type 1 diabetes (Flint et al. 2009). Epidemiological studies have reported a significant increase in the incidence of type 1 diabetes following a mumps epidemic (Hyoty et al. 1988). Unfortunately, not much evidence is available to clearly identify a correlation between mumps virus and type 1 diabetes. However, Cavallo et al. (1992) have shown that following mumps virus infection, MHC classes I and II were up-regulated, leading to a change in self-presentation and possibly leading to a decrease in tolerance towards $\beta$-cells, making them more susceptible to immunity-mediated destruction. The same study has also shown the induction of the secretion of IL1 and IL6. These cytokines are not responsible for the increase in the expression of MHC. However, they might play a role in the activation and proliferation of autoreactive $\mathrm{T}$ cells.

\section{Rubella virus}

A variety of studies have reported an association between rubella virus infection and type 1 diabetes. Furthermore, the percentage of individuals with islet autoantibodies has increased among patients suffering from congenital rubella syndrome (van der Werf et al. 2007). Studies have shown that rubella virus induces diabetes by direct infection of islet $\beta$-cells, leading to a decrease in the secretion of insulin (van der Werf et al. 2007). Alternatively, Ou et al. (2000) have demonstrated that the determinants of rubella virus cross-react with GADA-specific T cells in congenital rubella syndrome patients, who developed type 1 diabetes. These results are of great interest if the expression of GAD on $\beta$-cells is essential for the development of type 1 diabetes, as was shown in NOD mice (Yoon et al. 1999).

There is fairly good evidence that viruses, especially enteroviruses, may play a significant role in the development of type 1 diabetes via a variety of mechanisms. As in the hygiene hypothesis, a diabetogenic virus has not been identified still, and the difficulty still lies in the fact that the aetiological infection occurs years before the clinical onset. Therefore, this lag makes the identification very hard. The real question is as follows: can the viral hypothesis explain this increase in the incidence of type 1 diabetes? In the past 50 years, there has been a decrease in the incidence of infectious diseases, including mumps and tuberculosis, which can be justified by the introduction of vaccines, such as the BCG and mumps vaccines. Hyoty et al. (1993) reported a plateau effect in type 1 diabetes, following the introduction of the mumps/measles/rubella vaccine in Finland. However, this pattern has not been reported globally. Some epidemiological studies, such as those on the incidence of type 1 diabetes following a mumps epidemic, might be a coincidence since there have not been other studies reporting similar results. The viral hypothesis might provide a fairly good explanation for the pathogenic mechanisms leading to type 1 diabetes, but unfortunately there is too much controversy in this hypothesis to explain and to justify the rise in the incidence of this autoimmune disease.

\section{Vitamin D deficiency}

In a variety of epidemiological studies, type 1 diabetes appears to be conditioned by seasonal and geographical variation in u.v. light exposure (Kimpimaki et al. 2001, Mooney et al. 2004, Sloka et al. 2010).

Further support has come from Finnish studies, which have reported a decrease in incidence in children following vitamin D supplement induction (Hypponen et al. 2001) and an increase in incidence when supplementation is lowered (Mohr et al. 2010). However, contradictory evidence has come from more recent studies (Marjamaki et al. 2010, Simpson et al. 2011).

Vitamin D has come to be recognised to play a role in the modulation of the innate and adaptive immune system (Fig. 3). The activation of TLRs by pathogens causes an increased expression of vitamin $\mathrm{D}$ receptor (VDR) and the vitamin D-activating enzyme CP27B (25OHD-1 $\alpha$-hydroxylase) in macrophages (Adams \& Hewison 2008). Mitochondrial CP27B (also found in the classical renal proximal tubules) catalyses the conversion of $25 \mathrm{OHD}$ to $1,25(\mathrm{OH})_{2} \mathrm{D}_{3}$, which either binds to VDR or is secreted, inducing a variety of paracrine responses. VDRbound $1,25(\mathrm{OH})_{2} \mathrm{D}_{3}$ has three functions:

i) It acts as a transcriptional factor, inducing the expression of an antimicrobial polypeptide, cathelicidin. This will then be integrated in the pathogen-containing phagosome, leading to antimicrobial action.

ii) It leads to negative autoregulation by negative feedback of the enzymes CP24A and CP24A-SV.

iii) It causes negative autoregulation by the downregulation of TLRs.

Published by Bioscientifica Ltd. 


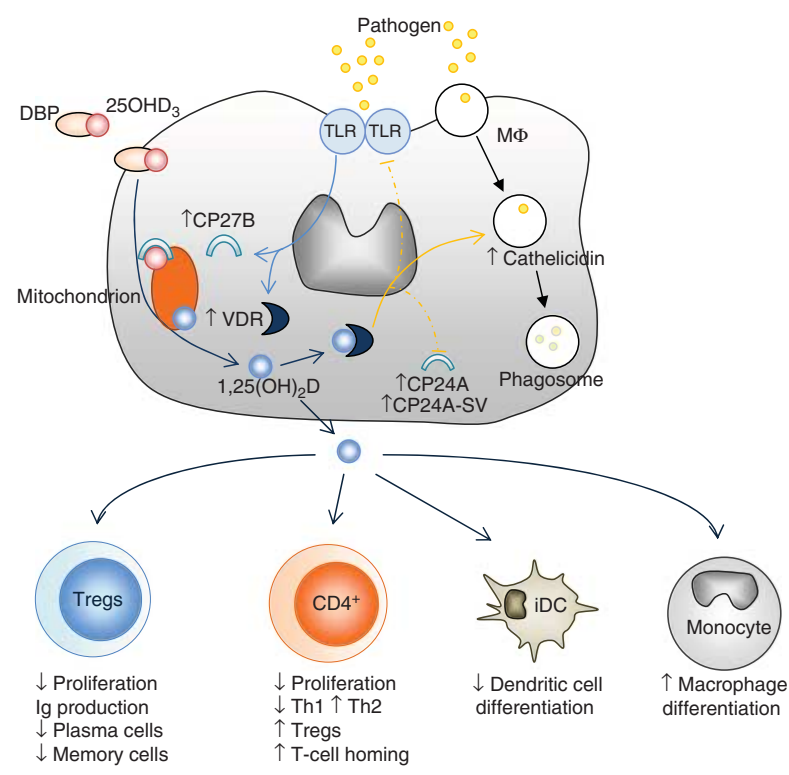

Figure 3

Role of vitamin $D$ in innate and adaptive immunity. $T L R$, toll-like receptor; $D B P$, vitamin D-binding protein; $C P 27 B, 250 \mathrm{HD}_{3}-1 \alpha$-hydroxylase; $C P 24 A$, $1,25(\mathrm{OH})_{2} \mathrm{D}_{3}$ 24-hydroxylase; $C P 24 A-S V, 1,25(\mathrm{OH})_{2} \mathrm{D}_{3}$ 24-hydroxylase splice variant; $V D R$, vitamin $D$ receptor; $25(\mathrm{OH}) D_{3}$, 25-hydroxycholecalciferol; $1,25(\mathrm{OH})_{2} \mathrm{D}_{3}, 1,25$-dihydroxycholecalciferol. Adapted from Adams JS \& Hewison M 2008 Unexpected actions of vitamin D: new perspectives on the regulation of innate and adaptive immunity. Nature Clinical Practice. Endocrinology \& Metabolism 4 80-90. Full colour version of this figure available via http://dx.doi.org/10.1530/JME-13-0067.

$1,25(\mathrm{OH})_{2} \mathrm{D}_{3}$ secreted by macrophages (or mature dendritic cells) induces a series of paracrine responses:

i) Activated $\mathrm{B}$ cells express high levels of VDR. $1,25(\mathrm{OH})_{2} \mathrm{D}_{3}$ causes a decrease in B-cell proliferation, antibody production, memory and plasma cells.

ii) Activated T cells express high levels of VDR as well, and activation by $1,25(\mathrm{OH})_{2} \mathrm{D}_{3}$ causes a decrease in proliferation and Th1 responses, but an increase in Th2 responses, Treg levels and T-cell homing.

iii) Monocytes, which express a higher number of VDRs than macrophages, stimulate further macrophage differentiation. Immature dendritic cells, which also contain a higher number of VDRs, cause the suppression of the differentiation of dendritic cells and an increase in the secretion of CC-chemokine ligand 22 (CCL22), which supports the synthesis of Tregs (Adams \& Hewison 2008).

Therefore, vitamin D plays an important role in the regulation of Th1 and Th2 balance, via the proliferation of Tregs and the release of cytokines.

What goes wrong when vitamin $\mathrm{D}$ is missing? Unfortunately, the exact mechanism is still unclear.
However, there is evidence from adult NOD mice that type 1 diabetes is inhibited following vitamin $\mathrm{D}$ analogue administration. In these models, vitamin D prevents the maturation of dendritic cells, therefore causing a decrease in the production of IL12. This has been shown to have an effect on the level of IFN $\gamma$ produced by Th1 cells, demonstrating a decrease in Th1 responses. This decrease has been associated with an increase in the frequency of $\mathrm{CD} 4{ }^{+} \mathrm{CD} 25^{+}$Tregs, arresting the development of type 1 diabetes. Further studies have provided similar evidence (Gregori et al. 2002). The study of Boonstra et al. (2001) has shown that vitamin D in mice not only inhibits the production of IFN $\gamma$ and therefore Th1 response, but also increases the Th2 response, leading to an increase in the production of IL4, IL5 and IL10. It has also demonstrated the direct effect of vitamin $\mathrm{D}$ on Th cells by activating naïve $\mathrm{CD} 4^{+} \mathrm{T}$ cells with anti-CD3 and anti-CD28. This leads to a significant rise in the levels of IL4, i.e. from 8 to $55.8 \%$. The Th2 transcription factors GATA3 and c-MAF (MAF) were found to be up-regulated as well. This indicates that vitamin $\mathrm{D}$ has a direct effect on Th cells, enhancing the development of Th 2 cells and therefore preventing the development of type 1 diabetes.

The last factor that might influence the development of the disease is genetic polymorphism of VDR. Vitamin D induces the formation of a VDR complex, which binds to vitamin D3 response elements. This normally has a variety of calcaemic and non-calcaemic activities, of which the inhibition of the expression of IL2, INF $\gamma$, TNF $\alpha$ and TNF $\beta$ is one (Nagpal et al. 2005). The gene encoding VDR has been identified to have four common variations: FokI, BsmI, ApaI, and TaqI. These alterations translate into functional VDR proteins, which in theory may lead to an abnormal synthesis of cytokines leading to type 1 diabetes. In fact, association has been found in Indian, Japanese, Taiwanese and German populations (Zella \& DeLuca 2003).

The vitamin D deficiency hypothesis has some flaws. First of all, countries that receive sufficient sunlight such as Kuwait and Sardinia (Italy) have an incidence similar to that of those countries at extreme latitudes: Finland, 40.9/100 000 per year and Sardinia, 37.8/100 000 per year. Furthermore, countries at a similar latitude may differ significantly, e.g. Finland and Russia (6.9/100 000 per year).

\section{Breast-feeding vs cow's milk hypotheses}

Borch-Johnsen et al. (1984) introduced the theory that insufficiency in breast-feeding of genetically susceptible children may lead to the development of $\beta$-cell infection and type 1 diabetes. A variety of studies have shown an

Published by Bioscientifica Ltd 
inverse correlation between a decrease in breast-feeding and the increase in type 1 diabetes risk (Borch-Johnsen et al. 1984, Scott 1990, Malcova et al. 2006).

Human milk seems to contain several molecules and cells that help prevent infection and possibly autoimmunity. Secretory IgA is present in great quantities in breast milk and plays a major role in the protection of organisms present in a neonate, since the collection of antibodies received is highly specific for the pathogens in the neonate's surroundings. Furthermore, it spares the gastrointestinal flora, providing further resistance. Other molecules involved are the antibacterial enzymes lysozyme and lactoferrin, which protect against bacteria (e.g. Escherichia coli and Staphylococcus). Human milk is also abundant in immune cells, such as leucocytes (neutrophils and macrophages), $\mathrm{T}$ and $\mathrm{B}$ cells, which play a major role in the immune defences of a neonate (Newman 1995). A variety of hormones can also be found, such as insulin, TGF $\alpha$ and macrophage colony-stimulating factor (M-CSF).

A possible mechanism is related to the presence of these specific GHs (TGF $\alpha$ and M-CSF), which are thought to support the maturation of the gastrointestinal tract. This is of great importance for the development of oral tolerance (Kolb \& Pozzilli 1999).

A second mechanism is the role of insulin in oral tolerance (Shehadeh et al. 2001). Wegmann \& Eisenbarth (2000) compared the two autoantibodies GADA and insulin in humans, demonstrating that the latter might be the primary antigen in the immune response to islets. Furthermore, oral administration of porcine insulin was found to suppress the onset of diabetes in NOD mice (Zhang et al. 1991). Human milk contains a large concentration of insulin, which is thought to play a major role in the maturation of mechanisms that regulate the intestinal permeability to macromolecules. This regulation is thought to modulate the exposure to triggering dietary proteins, such as caseins found in cow's milk, therefore reducing the triggering effect for an immune response (Shehadeh et al. 2001).

The last proposed mechanism is related to the regulatory role of cytokines present in breast milk. Ustundag et al. (2005) showed in their study the presence of a series of cytokines and trace elements in breast milk: IL1 $\beta$ (IL1B), IL2, IL6, IL8, TNF $\alpha$, zinc and copper. The presence of the different cytokines varied with lactation period. These data can be correlated with the protective effect observed in the study of Malcova et al. (2006), where early breast-feeding was shown to provide a greater protection. Therefore, one might hypothesise that early breast milk exposure might lead to an increase in the levels of neonatal cytokines (such as IL2), which, as seen in the hygiene hypothesis, might play a role in the protective action against type 1 diabetes.

Most papers, however, emphasise the role of cow's milk in the development of the disease. It has been shown that premature (by 3 months of age) exposure to cow's milk significantly increases the risk of developing the disease (Wasmuth \& Kolb 2000). However, other studies have provided discordance results, by showing no association. For example, Couper et al. (1999) followed 317 children with genetic predisposition from birth for 29 months. The relative risk of the introduction of products of cow's milk was between 0.91 and 1.09, and therefore the study concluded that there was no evidence for an association.

However, a variety of animal studies have confirmed the original theory. In fact, Johnston \& Monte (2000) demonstrated that early ingestion of cow's milk formula increased the incidence of diabetes in BB rats. They noticed acceleration in the development of the disease and a significant decrease in the mean age of onset.

But what makes cow's milk a triggering factor? A variety of studies have reported the association between antibodies against five major proteins present in cow's milk (caseins, $\alpha$-lactalbumin, $\gamma$-globulin, albumin and hormonal constituents) and the development of type 1 diabetes, but anti-BSA antibodies are the ones showing the highest disease specificity.

The link between cow's milk and the autoimmune process has been hypothesised to be due to molecular mimicry, breakdown of tolerance or lack of cytokines and growth factors.

\section{Molecular mimicry}

A hypothesis is the cross-reactivity between cow's milk proteins and $\beta$-cell autoantigens, resulting in the activation of autoreactive T cells. Honeyman et al. (1998) identified IA-2 epitope homologies, 60\% identity and 80\% similarity over ten amino acids, to casein in cow's milk. Knip et al. (2005) have suggested that cow's milk exposure causes a bovine insulin-induced immune response. They reported on a group of subjects in whom autoimmunity of the $\beta$-cells was associated with a continuous increase in the levels of bovine insulin IgG antibodies. This increase was explained by the cross-reactivity between the two types of insulin, shown by an increase in IAA levels. Another case of homology has been found between BSA and islet-cell antigen 69 (ICA69), which apparently modulate the progression of the disease in NOD mice (Kolb \& Pozzilli 1999).

Published by Bioscientifica Ltd. 


\section{Tolerance breakdown}

Another mechanism might be the breakdown of tolerance to dietary antigens induced by the immunoregulatory properties of cow's milk. $\beta$-Caseins present in cow's milk undergo hydrolysis to produce opiate-like peptides, called $\beta$-casomorphins (BMCs), which can have different forms. In fact, $\beta$-casein of Bos Taurus (A1) gives rise to BMC-7. Studies have shown that NOD mice progressed to develop diabetes following the administration of $\beta$-casein $A 1$, but not of $\beta$-casein A2. These fragments have an agonist effect on $\mu$-opioid receptors, leading to effects on the nervous, endocrine and gastrointestinal systems. Elitsur and Luk showed that BMCs inhibit the proliferation of lamina propria lymphocytes by the inhibition of DNA synthesis and ornithine decarboxylase activity, which are essential for the proliferation of both peripheral blood and lamina propria lymphocytes. Therefore, BCMs have an antiproliferative effect on LPL, possibly leading to the breakdown of tolerance. Furthermore, the paper has reported a series of studies on endorphins (endogenous opioid compounds), demonstrating an effect on human leucocytes and enhancing NK cell activity, T-cell cytotoxicity and IFN $\gamma$ production (Wasmuth \& Kolb 2000). Therefore, cow's milk might have an effect on the mucosal immune system by enhancing a Th1 response via APCs or by suppressing Tregs. This would lead to an overall decrease in mucosal tolerance.

Controversy in this hypothesis still remains, resulting from different outcomes in a variety of epidemiological, animal and human studies. This diversity, however, might be explained by the fact that only certain types of components in cow's milk are diabetogenic. Interestingly, a correlation exists between A1 (not A2) regional consumption and incidence of type 1 diabetes. One might hypothesise that genetic predisposition might lead to gastrointestinal mucosal immune responses, which will lead to the progression of the disease. This theory might be valid considering the fact that the immune system of the gut makes up two-thirds of the total lymphoid tissue in humans (Kolb \& Pozzilli 1999).

Another interesting point is the role of endorphins described above, whose direct association with diabetes has not been fully proven yet. However, similarities lead us to think that BMCs might really have an effect on immunocytes.

An overall reduction in breast-feeding is a well-known factor, highlighted by a series of epidemiological studies. The protective effect of human milk is still unclear; however, there is very good evidence that it plays a role in the immunological defences of a child's body against diabetes. The inverse correlation described initially by Borch-Johnsen et al. (1984) might after all be a plausible hypothesis. Further evidence that strengthens the argument is the lack of certain human milk components in cow's milk (and derivatives) that might influence the maturation of the gut.

\section{'Balance shift' model}

When observing the immunological mechanisms underlying each hypothesis (Table 1), one can notice certain similarities. When comparing one with the other, one can notice an opposing effect: protective vs diabetogenic. One can also realise that some common ground might exist between the various hypotheses, for instance, the role of TLRs in vitamin D deficiency and hygiene hypothesis. In fact, one might go as far as to suggest that vitamin D

Table 1 Comparison of the discussed hypothesis mechanisms: (A) hygiene hypothesis, (B) viral hypothesis and (C) vitamin D vs vitamin D deficiency and breast-feeding vs cow's milk hypotheses

\section{Hygiene hypothesis}

$\downarrow$ Bystander suppression

$\downarrow$ TLR activation

$\downarrow$ NKT cell activity

$\downarrow$ Competition

$\downarrow$ Autoreactive T-cell diversion

$\uparrow$ Autoreactive T-cell hyperactivation

Helminth eradication

Viral hypothesis

$\uparrow$ Bystander activation

Direct infection $\rightarrow$ cell lysis

Molecular mimicry

Self-presentation change

Tolerance breakdown

Successive activation

Vitamin D hypothesis

$\uparrow$ Antimicrobial effect

$\uparrow$ TLR activation

$\uparrow$ T-cell proliferation

$\downarrow$ Th1 cells

$\uparrow$ Th2 cells and Tregs

$\uparrow$ T-cell homing

B-cell proliferation, Ig, memory and plasma cells

$\uparrow$ Monocyte differentiation

$\downarrow$ Dendritic cells

Breast milk hypothesis

Vitamin D deficiency hypothesis

$\downarrow$ Antimicrobial effect

$\downarrow$ TLR activation

$\downarrow$ T-cell proliferation

$\uparrow$ Th1 cells

$\downarrow$ Th2 cells and Tregs

$\downarrow$ T-cell homing

$\uparrow$ B-cell proliferation, Ig, memory and plasma cells

$\downarrow$ Monocyte differentiation

$\uparrow$ Dendritic cells

Cow's milk hypothesis

$\uparrow$ Oral tolerance - GHs and insulin

$\uparrow$ Protective effect by cytokines

Published by Bioscientifica Ltd. 


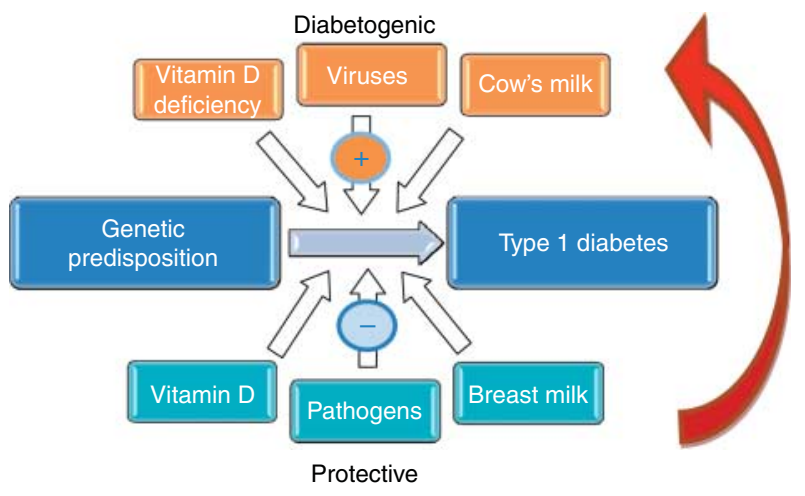

Figure 4

Summary of the 'balance shift' model. Protective factors (vitamin D, early exposure to pathogens and breast milk) are opposed by diabetogenic factors (vitamin D deficiency, viruses and cow's milk). In healthy individuals, a balance is maintained, but in patients suffering from type 1 diabetes, a shift towards diabetogenic factors occurs. Full colour version of this figure available via http://dx.doi.org/10.1530/JME-13-0067.

deficiency alters antimicrobial effect by modulating the function of TLRs. This alteration might also lead to a protective effect in a bystander manner. Oral tolerance induced by the protective action of human milk might compensate for dietary antigens introduced in the last century. As breast-feeding decreased throughout the 20th century, cow's milk formulas became more popular, leading to a negative shift in oral tolerance.

Taking the concept of protective vs diabetogenic factors, one might postulate that a compensatory mechanism might also occur between different hypothesised factors. In other words, an increase in vitamin $\mathrm{D}$ deficiency might be compensated by an increase in breast-feeding and so on. This compensation might be associated with a 'protective environment'. However, what would happen if most of the protective factors decreased? A shift might occur from a protective equilibrium towards an increase in diabetogenic factors, leading to type 1 diabetes. This change might have occurred gradually throughout the 20th century, leading to an increase in incidence. This concept is described as the 'balance shift' model, shown in Fig. 4.

A good analogy would be the use of a balancing scale with one plate on each side (each plate representing the diabetogenic and protective factors). Each plate supports a variety of weights, representing the various factors brought forward in the hypotheses described above. In healthy individuals, the weights are balanced at all times (Fig. 5A), meaning that if one of the protective weights becomes lighter, another protective one will compensate in order to maintain the scale in equilibrium (Fig. 5B). In diabetic patients, this compensatory mechanism does not occur, therefore tilting the scale towards the diabetogenic side (Fig. 5C).

It is likely that a multifactorial process leading to a disequilibrium between protective and diabetogenic factors is the cause of this increase. This in turn causes the acceleration of the diabetic process, causing an increase in childhood onset, therefore leading to an overall increase in the incidence of type 1 diabetes.

Further research, however, might be able to identify a common denominator, leading to a greater understanding as to why the incidence of type 1 diabetes is increasing.

A

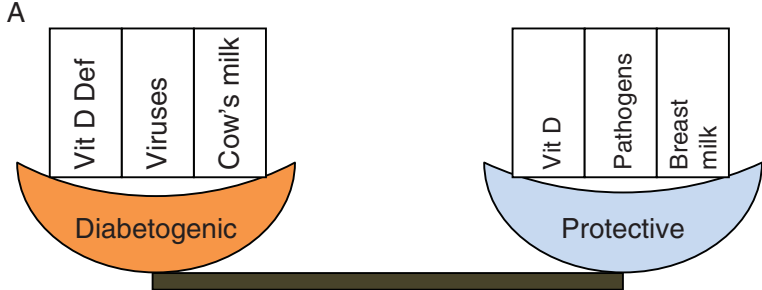

B
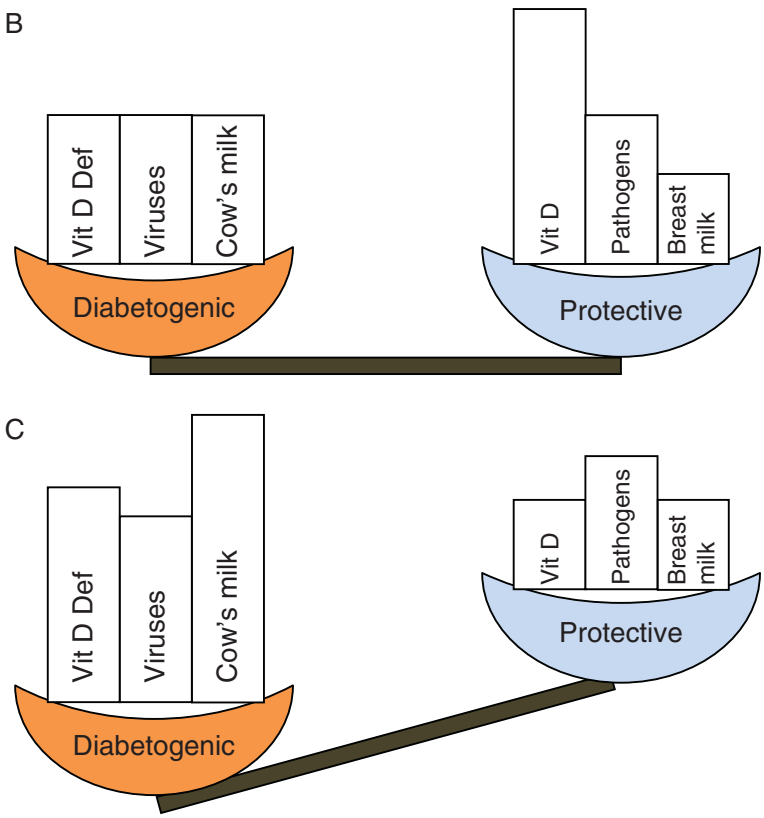

Figure 5

Analogy of the 'balance shift' model. (A) In healthy individuals, protective and diabetogenic factors are balanced at all times. (B) A change in this balance is normally compensated by other factors. For example, a decrease in breast-feeding might be compensated by an increase in vitamin D. (C) In diabetic patients, however, this compensatory mechanism does not occur, tilting the scale towards the diabetogenic side and therefore causing type 1 diabetes. Vit $D$, vitamin D; Def, deficiency. Full colour version of this figure available via http://dx.doi.org/10.1530/JME-13-0067.

Published by Bioscientifica Ltd. 


\section{Conclusion}

This review has tried to answer the following question: 'why is the incidence of type 1 diabetes increasing?' Although the hygiene hypothesis appears to be the most promising, there is too much positive evidence from animal, human and epidemiological studies to completely rule out any of the other hypotheses. Moreover, it is hard to believe that the same single factor is causing an increase in the incidence of diabetes all over the world. Evidence suggests that a multifactorial process might be involved. The immunological mechanisms are still unclear, but there seems to be some overlap between the various hypotheses. It is thought that the emphasis should be shifted from initiative to accelerative factors. Furthermore, a new theory, 'balance shift' model, has been brought forward to explain this rise.

Thus, the incidence of type 1 diabetes is increasing and we should be focusing on multiple mechanisms for its resolution.

\section{Declaration of interest}

The authors declare that there is no conflict of interest that could be perceived as prejudicing the impartiality of the review reported.

\section{Funding}

This review did not receive any specific grant from any funding agency in the public, commercial or not-for-profit sector.

\section{References}

Adams JS \& Hewison M 2008 Unexpected actions of vitamin D: new perspectives on the regulation of innate and adaptive immunity. Nature Clinical Practice. Endocrinology \& Metabolism 4 80-90. (doi:10.1038/ ncpendmet0716)

Atkinson MA, Bowman MA, Campbell L, Darrow BL, Kaufman DL \& Maclaren NK 1994 Cellular immunity to a determinant common to glutamate decarboxylase and coxsackie virus in insulin-dependent diabetes. Journal of Clinical Investigation 94 2125-2129. (doi:10.1172/ JCI117567)

Bach JF 2002 The effect of infections on susceptibility to autoimmune and allergic diseases. New England Journal of Medicine 347 911-920. (doi:10.1056/NEJMra020100)

Bach JF 2005 Infections and autoimmune diseases. Journal of Autoimmunity 25 (Suppl) 74-80. (doi:10.1016/j.jaut.2005.09.024)

Boonstra A, Barrat FJ, Crain C, Heath VL, Savelkoul HF \& O'Garra A 2001 $1 \alpha, 25$-Dihydroxyvitamin D3 has a direct effect on naive CD4(+) T cells to enhance the development of Th2 cells. Journal of Immunology $\mathbf{1 6 7}$ 4974-4980.

Borch-Johnsen K, Joner G, Mandrup-Poulsen T, Christy M, Zachau-Christiansen B, Kastrup K \& Nerup J 1984 Relation between breast-feeding and incidence rates of insulin-dependent diabetes mellitus. A hypothesis. Lancet 2 1083-1086. (doi:10.1016/S0140-6736 (84)91517-4)
Cavallo MG, Baroni MG, Toto A, Gearing AJ, Forsey T, Andreani D, Thorpe R $\&$ Pozzilli P 1992 Viral infection induces cytokine release by $\beta$ islet cells. Immunology 75 664-668.

Christen U, Benke D, Wolfe T, Rodrigo E, Rhode A, Hughes AC, Oldstone MB \& von Herrath MG 2004a Cure of prediabetic mice by viral infections involves lymphocyte recruitment along an IP-10 gradient. Journal of Clinical Investigation 113 74-84.

Christen U, Edelmann KH, McGavern DB, Wolfe T, Coon B, Teague MK, Miller SD, Oldstone MB \& von Herrath MG 2004b A viral epitope that mimics a self antigen can accelerate but not initiate autoimmune diabetes. Journal of Clinical Investigation 114 1290-1298.

Cooke A, Tonks P, Jones FM, O'Shea H, Hutchings P, Fulford AJ \& Dunne DW 1999 Infection with Schistosoma mansoni prevents insulin dependent diabetes mellitus in non-obese diabetic mice. Parasite Immunology 21 169-176. (doi:10.1046/j.1365-3024.1999.00213.x)

Coulson BS, Witterick PD, Tan Y, Hewish MJ, Mountford JN, Harrison LC \& Honeyman MC 2002 Growth of rotaviruses in primary pancreatic cells. Journal of Virology 76 9537-9544. (doi:10.1128/JVI.76.18.9537-9544. 2002)

Couper JJ, Steele C, Beresford S, Powell T, McCaul K, Pollard A, Gellert S, Tait B, Harrison LC \& Colman PG 1999 Lack of association between duration of breast-feeding or introduction of cow's milk and development of islet autoimmunity. Diabetes 48 2145-2149. (doi:10.2337/diabetes.48.11.2145)

DIAMOND Project Group 2006 Incidence and trends of childhood type 1 diabetes worldwide 1990-1999. Diabetic Medicine 23 857-866. (doi:10.1111/j.1464-5491.2006.01925.x)

Diana J, Brezar V, Beaudoin L, Dalod M, Mellor A, Tafuri A, von Herrath M, Boitard C, Mallone R \& Lehuen A 2011 Viral infection prevents diabetes by inducing regulatory T cells through NKT cell-plasmacytoid dendritic cell interplay. Journal of Experimental Medicine 208 729-745. (doi:10.1084/jem.20101692)

Dotta F, Censini S, van Halteren AG, Marselli L, Masini M, Dionisi S, Mosca F, Boggi U, Muda AO, Prato SD et al. 2007 Coxsackie B4 virus infection of $\beta$ cells and natural killer cell insulitis in recentonset type 1 diabetic patients. PNAS 104 5115-5120. (doi:10.1073/ pnas.0700442104)

Filippi CM \& von Herrath MG 2008 Viral trigger for type 1 diabetes: pros and cons. Diabetes 57 2863-2871. (doi:10.2337/db07-1023)

Flint SJ, Enquist LW \& Racaniello VR 2009 Principles of Virology. 3rd edition. Washington, DC (Great Britain): ASM Press.

Flodstrom M, Tsai D, Fine C, Maday A \& Sarvetnick N 2003 Diabetogenic potential of human pathogens uncovered in experimentally permissive $\beta$-cells. Diabetes 52 2025-2034. (doi:10.2337/diabetes.52.8.2025)

Fujinami RS, von Herrath MG, Christen U \& Whitton JL 2006 Molecular mimicry, bystander activation, or viral persistence: infections and autoimmune disease. Clinical Microbiology Reviews 19 80-94. (doi:10.1128/CMR.19.1.80-94.2006)

Gale EA 2002a A missing link in the hygiene hypothesis? Diabetologia 45 588-594. (doi:10.1007/s00125-002-0801-1)

Gale EA $2002 b$ The rise of childhood type 1 diabetes in the 20th century. Diabetes 51 3353-3361. (doi:10.2337/diabetes.51.12.3353)

Gregori S, Giarratana N, Smiroldo S, Uskokovic M \& Adorini L 2002 A $1 \alpha, 25$-dihydroxyvitamin $\mathrm{D}(3)$ analog enhances regulatory T-cells and arrests autoimmune diabetes in NOD mice. Diabetes 51 1367-1374. (doi:10.2337/diabetes.51.5.1367)

Harkonen T, Lankinen H, Davydova B, Hovi T \& Roivainen M 2002 Enterovirus infection can induce immune responses that cross-react with $\beta$-cell autoantigen tyrosine phosphatase IA-2/IAR. Journal of Medical Virology 66 340-350. (doi:10.1002/jmv.2151)

Honeyman MC, Stone NL \& Harrison LC 1998 T-cell epitopes in type 1 diabetes autoantigen tyrosine phosphatase IA-2: potential for mimicry with rotavirus and other environmental agents. Molecular Medicine 4 231-239.

Honeyman MC, Coulson BS, Stone NL, Gellert SA, Goldwater PN, Steele CE, Couper JJ, Tait BD, Colman PG \& Harrison LC 2000 Association 
between rotavirus infection and pancreatic islet autoimmunity in children at risk of developing type 1 diabetes. Diabetes 49 1319-1324. (doi:10.2337/diabetes.49.8.1319)

Honeyman MC, Stone NL, Falk BA, Nepom G \& Harrison LC 2010 Evidence for molecular mimicry between human $\mathrm{T}$ cell epitopes in rotavirus and pancreatic islet autoantigens. Journal of Immunology 184 2204-2210. (doi:10.4049/jimmunol.0900709)

Horwitz MS, Bradley LM, Harbertson J, Krahl T, Lee J \& Sarvetnick N 1998 Diabetes induced by coxsackie virus: initiation by bystander damage and not molecular mimicry. Nature Medicine 4 781-785. (doi:10.1038/ nm0798-781)

Horwitz MS, Ilic A, Fine C, Balasa B \& Sarvetnick N 2004 Coxsackieviralmediated diabetes: induction requires antigen-presenting cells and is accompanied by phagocytosis of $\beta$ cells. Clinical Immunology 110 134-144. (doi:10.1016/j.clim.2003.09.014)

Hyoty H, Leinikki P, Reunanen A, Ilonen J, Surcel HM, Rilva A, Kaar ML, Huupponen T, Hakulinen A, Makela AL et al. 1988 Mumps infections in the etiology of type 1 (insulin-dependent) diabetes. Diabetes Research 9 111-116.

Hyoty H, Hiltunen M, Reunanen A, Leinikki P, Vesikari T, Lounamaa R, Tuomilehto J \& Akerblom HK 1993 Decline of mumps antibodies in type 1 (insulin-dependent) diabetic children and a plateau in the rising incidence of type 1 diabetes after introduction of the mumps-measles-rubella vaccine in Finland. Childhood Diabetes in Finland Study Group. Diabetologia 36 1303-1308. (doi:10.1007/ BF00400810)

Hypponen E, Laara E, Reunanen A, Jarvelin MR \& Virtanen SM 2001 Intake of vitamin D and risk of type 1 diabetes: a birth-cohort study. Lancet 358 1500-1503. (doi:10.1016/S0140-6736(01)06580-1)

Johnston CS \& Monte WC 2000 Infant formula ingestion is associated with the development of diabetes in the BB/Wor rat. Life Sciences $6 \mathbf{6}$ 1501-1507. (doi:10.1016/S0024-3205(00)00467-7)

Kaufman DL, Erlander MG, Clare-Salzler M, Atkinson MA, Maclaren NK \& Tobin AJ 1992 Autoimmunity to two forms of glutamate decarboxylase in insulin-dependent diabetes mellitus. Journal of Clinical Investigation 89 283-292. (doi:10.1172/JCI115573)

Kimpimaki T, Kupila A, Hamalainen AM, Kukko M, Kulmala P, Savola K, Simell T, Keskinen P, Ilonen J, Simell O et al. 2001 The first signs of $\beta$-cell autoimmunity appear in infancy in genetically susceptible children from the general population: the Finnish Type 1 Diabetes Prediction and Prevention Study. Journal of Clinical Endocrinology and Metabolism 86 4782-4788. (doi:10.1210/jc.86.10.4782)

King C, Ilic A, Koelsch K \& Sarvetnick N 2004 Homeostatic expansion of $\mathrm{T}$ cells during immune insufficiency generates autoimmunity. Cell $\mathbf{1 1 7}$ 265-277. (doi:10.1016/S0092-8674(04)00335-6)

Knip M, Veijola R, Virtanen SM, Hyoty H, Vaarala O \& Akerblom HK 2005 Environmental triggers and determinants of type 1 diabetes. Diabetes 54 (Suppl 2) S125-S136. (doi:10.2337/diabetes.54.suppl_2.S125)

Kolb H \& Elliott RB 1994 Increasing incidence of IDDM a consequence of improved hygiene? Diabetologia 37 729. (doi:10.1007/BF00417700)

Kolb H \& Pozzilli P 1999 Cow's milk and type I diabetes: the gut immune system deserves attention. Immunology Today 20 108-110. (doi:10.1016/S0167-5699(98)01425-X)

Larsson PG, Lakshmikanth T, Svedin E, King C \& Flodstrom-Tullberg M 2013 Previous maternal infection protects offspring from enterovirus infection and prevents experimental diabetes development in mice. Diabetologia 56 867-874. (doi:10.1007/s00125-013-2834-z)

Liu Q, Sundar K, Mishra PK, Mousavi G, Liu Z, Gaydo A, Alem F, Lagunoff D, Bleich D \& Gause WC 2009 Helminth infection can reduce insulitis and type 1 diabetes through CD25- and IL-10-independent mechanisms. Infection and Immunity 77 5347-5358. (doi:10.1128/IAI.01170-08)

Lonnrot M, Korpela K, Knip M, Ilonen J, Simell O, Korhonen S, Savola K, Muona P, Simell T, Koskela P et al. 2000 a Enterovirus infection as a risk factor for $\beta$-cell autoimmunity in a prospectively observed birth cohort: the Finnish Diabetes Prediction and Prevention Study. Diabetes 49 1314-1318. (doi:10.2337/diabetes.49.8.1314)
Lonnrot M, Salminen K, Knip M, Savola K, Kulmala P, Leinikki P, Hyypia T, Akerblom HK \& Hyoty H $2000 b$ Enterovirus RNA in serum is a risk factor for $\beta$-cell autoimmunity and clinical type 1 diabetes: a prospective study. Childhood Diabetes in Finland (DiMe) Study Group. Journal of Medical Virology 61 214-220. (doi:10.1002/(SICI)10969071(200006)61:2<214::AID-JMV7>3.0.CO;2-9)

Malcova H, Sumnik Z, Drevinek P, Venhacova J, Lebl J \& Cinek O 2006 Absence of breast-feeding is associated with the risk of type 1 diabetes: a case-control study in a population with rapidly increasing incidence. European Journal of Pediatrics 165 114-119. (doi:10.1007/s00431-0050008-9)

Marjamaki L, Niinisto S, Kenward MG, Uusitalo L, Uusitalo U, Ovaskainen ML, Kronberg-Kippila C, Simell O, Veijola R, Ilonen J et al. 2010 Maternal intake of vitamin D during pregnancy and risk of advanced $\beta$ cell autoimmunity and type 1 diabetes in offspring. Diabetologia 53 1599-1607. (doi:10.1007/s00125-010-1734-8)

Mohr SB, Garland FC, Garland CF, Gorham ED \& Ricordi C 2010 Is there a role of vitamin D deficiency in type 1 diabetes of children? American Journal of Preventive Medicine 39 189-190. (doi:10.1016/j.amepre.2010. $03.023)$

Mooney JA, Helms PJ, Jolliffe IT \& Smail P 2004 Seasonality of type 1 diabetes mellitus in children and its modification by weekends and holidays: retrospective observational study. Archives of Disease in Childhood 89 970-973. (doi:10.1136/adc.2003.040865)

Nagpal S, Na S \& Rathnachalam R 2005 Noncalcemic actions of vitamin D receptor ligands. Endocrine Reviews 26 662-687. (doi:10.1210/er. 2004-0002)

Newman J 1995 How breast milk protects newborns. ProMoM, Inc.

Oikarinen M, Tauriainen S, Honkanen T, Oikarinen S, Vuori K, Kaukinen K, Rantala I, Maki M \& Hyoty H 2008 Detection of enteroviruses in the intestine of type 1 diabetic patients. Clinical and Experimental Immunology 151 71-75. (doi:10.1111/j.1365-2249.2007.03529.x)

Onkamo P, Vaananen S, Karvonen M \& Tuomilehto J 1999 Worldwide increase in incidence of type I diabetes - the analysis of the data on published incidence trends. Diabetologia 42 1395-1403. (doi:10.1007/ s001250051309)

Ou D, Mitchell LA, Metzger DL, Gillam S \& Tingle AJ 2000 Cross-reactive rubella virus and glutamic acid decarboxylase (65 and 67) protein determinants recognised by $\mathrm{T}$ cells of patients with type I diabetes mellitus. Diabetologia 43 750-762. (doi:10.1007/s001250051373)

Poulton LD, Smyth MJ, Hawke CG, Silveira P, Shepherd D, Naidenko OV, Godfrey DI \& Baxter AG 2001 Cytometric and functional analyses of NK and NKT cell deficiencies in NOD mice. International Immunology $\mathbf{1 3}$ 887-896. (doi:10.1093/intimm/13.7.887)

Qin HY, Chaturvedi P \& Singh B 2004 In vivo apoptosis of diabetogenic T cells in NOD mice by IFN- $\gamma / \mathrm{TNF}-\alpha$. International Immunology $\mathbf{1 6}$ 1723-1732. (doi:10.1093/intimm/dxh173)

Quintana FJ, Rotem A, Carmi P \& Cohen IR 2000 Vaccination with empty plasmid DNA or CpG oligonucleotide inhibits diabetes in nonobese diabetic mice: modulation of spontaneous $60-\mathrm{kDa}$ heat shock protein autoimmunity. Journal of Immunology 165 6148-6155.

Richter W, Mertens T, Schoel B, Muir P, Ritzkowsky A, Scherbaum WA \& Boehm BO 1994 Sequence homology of the diabetes-associated autoantigen glutamate decarboxylase with coxsackie B4-2C protein and heat shock protein 60 mediates no molecular mimicry of autoantibodies. Journal of Experimental Medicine 180 721-726. (doi:10.1084/jem.180.2.721)

Scott FW 1990 Cow milk and insulin-dependent diabetes mellitus: is there a relationship? American Journal of Clinical Nutrition $\mathbf{5 1} 489-491$.

Serreze DV, Ottendorfer EW, Ellis TM, Gauntt CJ \& Atkinson MA 2000 Acceleration of type 1 diabetes by a coxsackievirus infection requires a preexisting critical mass of autoreactive T-cells in pancreatic islets. Diabetes 49 708-711. (doi:10.2337/diabetes.49.5.708)

Shehadeh N, Shamir R, Berant M \& Etzioni A 2001 Insulin in human milk and the prevention of type 1 diabetes. Pediatric Diabetes 2 175-177. (doi:10.1034/j.1399-5448.2001.20406.x) 
Simpson M, Brady H, Yin X, Seifert J, Barriga K, Hoffman M, Bugawan T, Baron AE, Sokol RJ, Eisenbarth G et al. 2011 No association of vitamin D intake or 25-hydroxyvitamin D levels in childhood with risk of islet autoimmunity and type 1 diabetes: the Diabetes Autoimmunity Study in the Young (DAISY). Diabetologia $\mathbf{5 4} 2779-2788$. (doi:10.1007/ s00125-011-2278-2)

Sloka S, Grant M \& Newhook LA 2010 The geospatial relation between UV solar radiation and type 1 diabetes in Newfoundland. Acta Diabetologica 47 73-78. (doi:10.1007/s00592-009-0100-0)

Smelt MJ, Faas MM, de Haan BJ, Draijer C, Hugenholtz GC, de Haan A, Engelse MA, de Koning EJ \& de Vos P 2012 Susceptibility of human pancreatic $\beta$ cells for cytomegalovirus infection and the effects on cellular immunogenicity. Pancreas 41 39-49. (doi:10.1097/MPA. Ob013e31821fc90c)

Soltesz G, Patterson CC \& Dahlquist G 2007 Worldwide childhood type 1 diabetes incidence - what can we learn from epidemiology? Pediatric Diabetes 8 (Suppl 6) 6-14. (doi:10.1111/j.1399-5448.2007.00280.x)

Strachan DP 1989 Hay fever, hygiene, and household size. BMJ 299 1259-1260. (doi:10.1136/bmj.299.6710.1259)

Takei I, Asaba Y, Kasatani T, Maruyama T, Watanabe K, Yanagawa T, Saruta T \& Ishii T 1992 Suppression of development of diabetes in NOD mice by lactate dehydrogenase virus infection. Journal of Autoimmunity 5 665-673. (doi:10.1016/0896-8411(92)90184-R)

Theofilopoulos AN, Dummer W \& Kono DH 2001 T cell homeostasis and systemic autoimmunity. Journal of Clinical Investigation 108 335-340.

Tracy S, Drescher KM, Chapman NM, Kim KS, Carson SD, Pirruccello S, Lane PH, Romero JR \& Leser JS 2002 Toward testing the hypothesis that group B coxsackieviruses (CVB) trigger insulin-dependent diabetes: inoculating nonobese diabetic mice with CVB markedly lowers diabetes incidence. Journal of Virology 76 12097-12111. (doi:10.1128/JVI.76.23. 12097-12111.2002)

Tracy S, Drescher KM, Jackson JD, Kim K \& Kono K 2010 Enteroviruses, type 1 diabetes and hygiene: a complex relationship. Reviews in Medical Virology 20 106-116. (doi:10.1002/rmv.639)
Ustundag B, Yilmaz E, Dogan Y, Akarsu S, Canatan H, Halifeoglu I, Cikim G \& Aygun AD 2005 Levels of cytokines (IL-1 $\beta$, IL-2, IL-6, IL-8, TNF- $\alpha$ ) and trace elements $(\mathrm{Zn}, \mathrm{Cu})$ in breast milk from mothers of preterm and term infants. Mediators of Inflammation 2005 331-336. (doi:10.1155/ MI.2005.331)

Wasmuth HE \& Kolb H 2000 Cow's milk and immune-mediated diabetes. Proceedings of the Nutrition Society 59 573-579. (doi:10.1017/ S0029665100000811)

Wegmann DR \& Eisenbarth GS 2000 It's insulin. Journal of Autoimmunity 15 286-291. (doi:10.1006/jaut.2000.0444)

van der Werf N, Hillebrands JL, Klatter FA, Bos I, Bruggeman CA \& Rozing J 2003 Cytomegalovirus infection modulates cellular immunity in an experimental model for autoimmune diabetes. Clinical \& Developmental Immunology 10 153-160. (doi:10.1080/ 10446670310001626490)

van der Werf N, Kroese FG, Rozing J \& Hillebrands JL 2007 Viral infections as potential triggers of type 1 diabetes. Diabetes/Metabolism Research and Reviews 23 169-183. (doi:10.1002/dmrr.695)

Yeung WC, Rawlinson WD \& Craig ME 2011 Enterovirus infection and type 1 diabetes mellitus: systematic review and meta-analysis of observational molecular studies. BMJ 342 d35. (doi:10.1136/bmj.d35)

Yoon JW, Yoon CS, Lim HW, Huang QQ, Kang Y, Pyun KH, Hirasawa K, Sherwin RS \& Jun HS 1999 Control of autoimmune diabetes in NOD mice by GAD expression or suppression in $\beta$ cells. Science $\mathbf{2 8 4}$ 1183-1187. (doi:10.1126/science.284.5417.1183)

Zaccone P, Burton OT, Gibbs S, Miller N, Jones FM, Dunne DW \& Cooke A 2010 Immune modulation by Schistosoma mansoni antigens in NOD mice: effects on both innate and adaptive immune systems. Journal of Biomedicine \& Biotechnology 2010795210.

Zella JB \& DeLuca HF 2003 Vitamin D and autoimmune diabetes. Journal of Cellular Biochemistry 88 216-222. (doi:10.1002/jcb.10347)

Zhang ZJ, Davidson L, Eisenbarth G \& Weiner HL 1991 Suppression of diabetes in nonobese diabetic mice by oral administration of porcine insulin. PNAS 88 10252-10256. (doi:10.1073/pnas.88.22. 10252)

Received in final form 28 May 2013

Accepted 3 June 2013

Accepted Preprint published online 3 June 2013
(C) 2013 Society for Endocrinology Printed in Great Britain 